THE INTERNATIONAL

REVIEW OF RESEARCH IN

OPEN AND DISTANCE LEARNING

\title{
Emotional Presence, Learning, and the Online Learning Environment
}

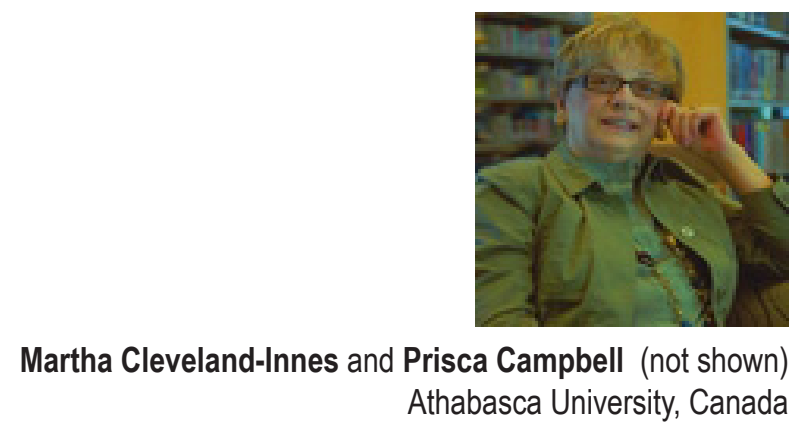

\section{Abstract}

In spite of evidence that more and more students are engaging in online learning experiences, details about the transition for teachers and students to a new learning environment are still unconfirmed. While new technologies are often expected to make work easier, they also involve the development of new competencies. This change may, in itself, elicit an emotional response, and, more importantly, emotion may impact the experience of online learning. Knowledge about the impact of emotion on learning broadly is available, but not about emotion and online learning. This study presents evidence of emotions present in online environments, and empirical data which suggests emotional presence may exist as a fundamental element in an online community of inquiry.

Keywords: Online learning; community of inquiry; emotional presence; higher education; distance education; pedagogy

\section{Introduction}

General wisdom has it that emotion is antithetical to thinking; the coolest head prevails (Barbalet, 2002). This may be the reason that, until recently, emotion and learning have received little attention in the development of education and instructional models. We may have Bloom and colleagues to thank for introducing us to the notion of affect as a learning domain (Krathwohl, 2002; Morrison, Ross, \& Kemp, 2004). Previous studies suggest that teaching and learning with technology has a small, positive, nonsignificant ( $p>.05$ ) effect on students' affective outcomes when compared to traditional instruction. (Waxman, Lin, \& Michko, 2003). However, the notion of affect, defined as the extent to which one can be influenced and affected (Davidson, 2003; Gronlund, 2000), is much different from the issue of emotion and its impact on learning-impact that may exist in all activities and do- 
mains of learning (Gardner, Kornhaber, \& Wake, 1996). To engage in education innovation with no reference to emotion, and continue to assume learners are little more than dispassionate thinkers, would be to miss a fundamental influence on education.

Bowlby provides the definition of emotion most amenable to understanding in reference to learning. He says, "Emotions are phases of an individual's intuitive appraisals either of his own organismic states and urges to act or of the succession of environmental situations in which he finds himself" (1969, p. 104). For some, emotions exist comprehensively in the human experience; to ignore emotion in the human response to internal and external events is to ignore a central element of the human experience (LeDoux, 1996; Plutchick, 2003; Stets \& Turner, 2006; Wosnitza \& Volet, 2005). Emotion, therefore, cannot be considered separate from the learning environment (Brookfield, 2006; Lehman, 2006; Lipman, 2003). New research regarding the impact of emotion and cognition provides compelling evidence that the relationship between emotion and learning should be examined further (Damasio, 1994, 1995, 1999, 2003; Dirkx, 2008; Dirkx \& Cranton, 1997; Eich, Kihlstrom, Bower, Forgas, \& Niedenthal, 2000; LeDoux, 1996).

Given this new information about cognition and emotion, we developed a working hypothesis that emotion plays a role in learning and, therefore, will be present in online learning environments. In addition, Dirkx (2008) made a case for the integration of feeling into adult education. That impassioned argument was the impetus for this examination of the role of emotion in online learning.

Our research unfolded in two phases. The first question we set out to answer is which, if any, emotions exist in the online learning environment. Phase II of our research is a reconsideration of the role of emotion in the conceptual model of online learning proposed by Garrison, Anderson, and Archer (2000). The online community of inquiry framework served as a tool to analyze and categorize the existence of emotion across elements of the online learning experience.

\section{Background Information}

Given that emotions exist in the broader, comprehensive human experience (Plutchick, 2003), they cannot be considered separate from the experience of the learning environment (Brookfield, 2006; Lehman, 2006). Recently, there has been an increasing focus on emotion and learning, which has been generally neglected in educational research (Schutz \& Lanehart, 2002; Pekrun, Goetz, Titz, \& Perry, 2002; Dirkx, 2008; Värlander, 2008). Moreover, Brookfield (2006) and Dirkx (2008) suggest that emotion is often mistaken as a deterrent that impedes effective teaching and learning. It is likely that emotion plays a far more dynamic role in learning than merely inhibiting rational thought and reason. An understanding of the nature of emotions in the learning context may assist the learning process as all human actions and reasoning "require appropriate facilitating emotions if successful actions or reason at all are to be achieved [emphasis added]" (Barbalet, 2002, p. 1). 


\section{Emotion and learning.}

When LeDoux (2002) began researching emotion in the 1970s, he chose to study fear "because it is the emotion about which we know the most" (p. 212). He assumed that what he learned would likely "be similar across emotion categories" (p. 212). At the same time LeDoux was studying emotion in rats, Damasio (1994) noticed the importance of emotion in the human experience. A neuroscientist, Damasio made his life's work the study of emotion and the human brain, using as his subjects people whose brains were damaged through accident, surgery, or birth. His observations of a patient referred to as Elliot, who had lost his ability to draw conclusions, led him to reconsider the role of emotion in rational thought. Elliot was a brilliant lawyer, well known for his complex reasoning abilities and his ability to defend clients with intricate argument. Elliot had an accident that damaged his ability to experience emotion. Damasio became intrigued with the possibility that reduced emotion and feeling played a role in Elliot's decision-making failures (p. 145).

This work did not go unnoticed in education. "In recent years, there has been a growing interest in the role of emotions in academic settings, especially in how emotions shape student engagement and learning" (Linnenbrink-Garcia \& Pekrun, 2011, p. 1). Educational psychology has long considered motivation, particularly achievement motivation in relation to education performance, to be related to emotion (Weiner, 1985; Artino, 2009; Artino \& Stephens, 2006). Callahan (2004) called for educators who espouse critical theory to "manage the emotions in their classrooms actively" (p. 82). He pointed out that "the very praxis of critical theory relies on emotion as its catalyst" (p. 75). Dirkx (personal communication, 2005) questioned the appropriateness of "management" of emotion in learning environments. However, the impact on particular emotional states in relation to the learning environment is still to be understood.

Merriam and Heuer (1996) recognized that feelings of threat and fear are intrinsic in learning. Goleman (1995, p. 27), writing of face-to-face learning, described the connection between emotion and cognition as a "battle," with the brain at the epicentre. One consequence of this battle is paradoxical. "Sometimes stress helps in formation of explicit memories but it can also devastate explicit memory" (LeDoux (1996, p. 243). Emotions, then, are a double-edged sword that may help or hinder learning.

Dirkx (1998) called for the recognition of the positive emotions engendered by learning. Furthermore, he suggested that critical theory failed to "adequately account for the emotional and spiritual dimensions (para. 1)" of learning. At about the same time, Gardner (1998), Goleman (1995, 1998), and LeDoux (1996) rethought the significance of emotion. Concurrently, Damasio $(1994,1995)$ conducted experiments that indicate that emotion and cognition are innately intertwined. Although other researchers are beginning to build on

the work of Damasio and his team, "inquiry has been slow to advance our understanding of emotions in education" (Schutz \& Lanehart, 2002, p. 67). Learning processes are the currency of exchange in education, and emotional experiences are a "neglected dynamic" (Ingleton, 2000, p. 86) in complex social environments where learning takes place. This is particularly so in online learning. According to O'Regan (2003), the transition to online 
teaching and learning provides the opportunity to test the assumptions about emotion embedded in our practice, building on the strands of research developed regarding emotion and the human experience, emotion and cognition, and, more recently, emotion and learning.

\section{Emotion and Online Learning}

Lipman (2003) provides one exception to what has been a neglectful approach to emotion. He explicitly writes about emotion while describing learning through a community of inquiry. For Lipman, the community of inquiry model is "thoroughly social and communal; a method for integrating emotive experience, mental acts, thinking skills, and informal fallacies into a concerted approach to the improvement of reasoning and judgment [emphasis added]" (p. 18). Another exception to the neglect is the application of this same model in online learning by Garrison, Anderson, and Archer (2000), who identify emotional expression as part of being socially present online.

This model explicating teaching practice and student learning online is the community of inquiry (CoI) framework developed by Garrison, Anderson, and Archer (2000). This model has received significant attention and has been well researched (Akyol et al., 2009; Arbaugh et al., 2009). It provides a process-oriented, conceptual model that informs the practice of online instruction.

The model views community as something that emerges in support of online learning (Rovai, 2002; Thompson \& MacDonald, 2005; Shea, 2006) in the relationship between three elements: social presence, teaching presence, and cognitive presence. Social presence is defined as the degree to which learners feel socially and emotionally connected with others in an online environment; cognitive presence describes the extent to which learners are able to construct and confirm meaning through sustained reflection and discourse. The central organizing element is teaching presence: the design, facilitation, and, most importantly, the direction of cognitive and social processes for the realization of personally meaningful and educationally worthwhile learning outcomes. The possibility of an expanded role for emotional presence, beyond the influence found in social presence, is central to this research.

The creative innovation that follows the development of online learning provides a unique place for the study of emotional presence and learning. As indicated by Anderson (2007), seven of fifteen indicators of social expression are expressions of emotion. Emotion is identified as important to student adjustment to the role of online learner (Cleveland-Innes, Garrison \& Kinsel, 2007), the development of online community (Perry \& Edwards, 2005), the choice of instructional format (Artino, 2010), and perception, expression, and selfmanagement (Kang, Kim, \& Park, 2007). Conrad (2002), in her study of emotion, vividly recounted the tumult of feelings, including anxiety, that accompany the online learning experience.

Those engaged in online learning deal with the effects of emotion on a daily basis, whether in designing instruction, teaching, or learning online. The work of Damasio and LeDoux independently suggests that emotion is neither an objective nor outcome of learning yet is 
central to cognition. The study of O'Regan (2003) showed that students express their emotions in relation to the various aspects of an online course such as design and organizational issues (i.e., a lack of clear instructions), cognitive issues (i.e., learning materials, success), social issues (during communicating), time management, or technology. Similarly, Cleveland-Innes, Garrison, and Kinsel (2007) also found out that students disclosed emotions in relation to the social, teaching, and cognitive presence in an online course.

Zembylas (2008) applied qualitative methodology to investigate emotional presence, using learners' monthly emotion journals and interview strategy. The analysis resulted in two broad themes: positive and negative emotions related to learning. Positive emotions included joy, enthusiasm, and excitement for the flexibility of online learning, which were higher in intensity and frequency in earlier months; pride and contentment for fulfilling the course requirements; and surprise and excitement for the emotional nature of online communication. Negative emotions included fear and anxiety for the unknown mode of online learning and its demands (technology, time management, structure); alienation and the need for connectedness, which emerged during the first weeks of the course and when the students struggled to find satisfying ways of communicating with their classmates and their instructor; and stress and guilt for the inability to balance multiple roles and responsibilities, which is the most serious obstacle that the students faced. They struggled to combine their professional, family, and social life, which made it hard to cope with the numerous demands of the program.

Research results from multiple studies indicate that emotions are an integral part of the learning environment and influence students' learning experiences (Cleveland-Innes \& Campbell, 2006). According to Baumeister, DeWall, and Zhang (2007), emotions influence outcomes. That is, positive emotions lead to positive outcomes and negative emotions to negative outcomes. The research also indicates the impeding effect of negative emotions such as stress and anger. Evidence suggests that negative emotions, such as anger and embarrassment, can influence decision making and lead people to take inappropriate risks (Baumeister et al., 2007).

In addition, excessive emotion can harm our rational thinking, and a lack of emotion can make for similarly flawed thinking (Cottrell, 2005). All these aspects come together and create a new challenge for educators in determining how to best integrate and control emotions in a learning environment. This is especially so in reference to the adjustment process that occurs as students move online. Experiencing negative emotions during adjustment to the role of online learner may interfere with the learning experience. Thoughtful consideration of emotions and possible facilitation strategies in response to negative emotions during the online adjustment process are both timely and important. 


\section{Methodology}

\section{Sample of Courses and Respondents}

Students participating in this study were enrolled in two graduate programs at a singlemode distance education university. A total of 217 students from 19 courses agreed to participate. Courses were drawn from education, humanities, science, social science, and science, and all were delivered online. Of the 217 students consenting to participate, $33 \%$ were male and $58 \%$ were female ( $9 \%$ did not indicate gender). Respondents indicated their age as follows: $20-29$ years, $10 \%$, 30-39 years, $24 \%$, 40-49 years, $43 \%$, 50+ years, $23 \%$. Fortysix percent of the participants reported this as their first experience in an online learning environment $(n=73)$.

Additional data were collected from students in the same graduate programs using a modified CoI instrument (Arbaugh et al., 2009). The modified instrument includes previously validated item indicators for cognitive, social, and teaching presence, with the addition of new measures for emotional presence.

To qualify for sampling, courses had to be delivered using a combination of print and electronic media and online conferencing. The online conferencing component had to provide the opportunity for regular student engagement and group interaction.

\section{Data Collection}

In the first phase of data collection, students were asked to 1) provide access to conference discussion transcripts, and 2) complete a survey of questions regarding his/her online experience. Conference discussion transcripts were collected at the end of each course. Written, detailed responses were gathered from open-ended questions related to online activities, becoming part of the online learning community and the design and facilitation of online learning. Secondary data analysis of open-ended questions and conference transcripts, originally assessed for alignment with the expectations of online learners, were evaluated for emotional content. Text analysis was completed with four individual raters using open, axial, and confirmatory analysis (Neuman, 2006). Inter-rater reliability ranged from $66 \%$ to $80 \%$.

Once we confirmed evidence of emotional content in text about online learning and text found in conference discussions in online learning, we set out to measure whether emotion was present in one or more elements of an online community of inquiry, as proposed by Garrison, Anderson, and Archer (2000). The academic and social domains are represented in the online CoI model and measurement tool by three elements called presences: social, cognitive, and teaching presence. A similar convenience sample of seven courses was chosen from the same two graduate programs at the same university. A response rate of $38 \%$ yielded 79 completed questionnaires. The online CoI measurement instrument (Arbaugh et al., 2009) was employed, with six additional items written to measure the possibility of emotional presence. The instrument was available online through Zoomerang online survey software and self-administered by students. The possibility of response-set bias was 
deterred by randomizing items measuring different types of presence.

Exploratory factor analysis (principal components extraction method) with an oblimin rotation was used. An oblimin rotation was chosen due to the theoretical interdependence of the presences. The cutoff point for significant loadings on each factor was 0.350 .

\section{Findings}

The unit of analysis for the present study is the student, in Phase I via the text-based response and in Phase II via indications of presence. Qualitative data, drawn from openended questions about the online experience, were evaluated by four different coders using a grounded theory analysis process of open, axial, and confirmatory coding. After the first read-through of all documentation, coders discussed the range of emotions noted in the textual data and discussed the use of terms to label expressions deemed to be 'emotional.' A preliminary list of terms was created. Data were reassessed using new terminology. Table 1 presents the list of identifiable emotional responses found in questionnaire responses and conference postings. 
Table 1

Emotional Responses Identified in Text Data

\begin{tabular}{|c|c|c|}
\hline Constructs & Written responses to questions & $\begin{array}{l}\text { Asynchronous conference tran- } \\
\text { scripts }\end{array}$ \\
\hline Appreciation & & $\mathrm{X}$ \\
\hline Delight & & $\mathrm{X}$ \\
\hline Desire & $\mathrm{X}$ & $\mathrm{X}$ \\
\hline Disappointment & $\mathrm{X}$ & \\
\hline Dislike & & $\mathrm{X}$ \\
\hline Emphatics & $\mathrm{X}$ & $\mathrm{X}$ \\
\hline Enjoyment & $\mathrm{X}$ & $\mathrm{X}$ \\
\hline Excitement & $\mathrm{X}$ & $\mathrm{X}$ \\
\hline Fear & $\mathrm{X}$ & \\
\hline Frustration & $\mathrm{X}$ & \\
\hline Happiness & $\mathrm{X}$ & \\
\hline Hope & & $\mathrm{X}$ \\
\hline Humour & $\mathrm{X}$ & $\mathrm{X}$ \\
\hline Irony/sarcasm & & $\mathrm{X}$ \\
\hline Like & & $\mathrm{X}$ \\
\hline Passion & $\mathrm{X}$ & $\mathrm{X}$ \\
\hline Preference & & $\mathrm{X}$ \\
\hline Pride & $\mathrm{X}$ & $\mathrm{X}$ \\
\hline Surprise & $\mathrm{X}$ & \\
\hline Thankfulness & & $\mathrm{X}$ \\
\hline Unhappiness & $\mathrm{X}$ & $\mathrm{X}$ \\
\hline Wonder & $\mathrm{X}$ & \\
\hline Yearning & $\mathrm{X}$ & $\mathrm{X}$ \\
\hline
\end{tabular}

These constructs were attached to student responses deemed to represent emotive description. Each label emerged after multiple passes through the text, and much discussion. Confirmation was achieved in two ways. Coders reached agreement regarding the labels presented here. In addition, the pattern of emotions was measured against the taxonomy of human emotions, as defined by Plutchick (2003).

Phase II of the data collection used a questionnaire administered as an online survey. Students in the same courses were invited to respond to item indicators, on a Likert scale of Strongly Agree, Agree, Undecided, Disagree, or Strongly Disagree. These items are drawn from the original online CoI measurement instrument measuring social presence, cognitive presence, and teaching presence (Arbaugh et al., 2009). 
The revised instrument included an additional six items designed to measure emotional presence. The items listed below were written to assess emotional response in relation to the instructor, the other students, the technology, and the course:

- Emotion was expressed when connecting with other students.

- I felt comfortable expressing emotion through the online medium.

- Expressing emotion in relation to expressing ideas was acceptable in this course.

- I found myself responding emotionally about ideas or learning activities in this course.

- The instructor acknowledged emotion expressed by students.

- The instructor demonstrated emotion in online presentations and/or discussions.

Factor analysis rests on the logic that it is possible to assess patterns in relative variances of measured items such that underlying, hypothesized theoretical constructs will emerge. This analysis was completed to determine if the items measuring emotional presence would cluster together in a unique component. The extraction method was a principal components analysis with an oblimin rotation. This yielded a nine-factor solution in which four of the six items measuring emotional presence clustered into a single factor. The remaining items measuring the other three presences clustered as expected based on the theoretical model. However, the addition of emotional presence items did affect the clustering of factors, as indicated in Table 2. Items in this table are identified by the presence and sub-element they are designed to measure. ${ }^{1}$

Table 2

Factor Analysis - Nine Components

Component

1 23 34

56

7

8

V24 - TP Design and Organization

The instructor provided clear instructions on how to .919 participate in course learning activities.

V7 - TP Design and Organization

The instructor clearly communicated important course .891 goals.

1 Recent research demonstrates that the general rules of thumb regarding minimum sample size are not valid or useful (MacCallum, Widaman, Zhang, \& Hong, 1999; Preacher \& MacCallum, 2002). 
V15 - TP Design and Organization

The instructor clearly communicated important course

topics.

V5 - TP Design and Organization

The instructor clearly communicated important due .601 dates/time frames for learning activities.

V33 - SP Group Cohesion

Online discussions help me to develop a sense of collaboration.

V20 - TP Facilitation

The instructor helped keep the course participants on .566 task in a way that helped me to learn.

V10 - TP Facilitation

The instructor was helpful in identifying areas of agreement and disagreement on course topics that .473 helped me to learn.

V29 - TP Direct Instruction

The instructor helped to focus discussion on relevant .440 issues in a way that helped me to learn.

V2 - TP Facilitation

Instructor actions reinforced the development of a .401 sense of community among course participants.

V40 - Emotion

I found myself responding emotionally about ideas or .372 learning activities in this course.

V9 - TP Direct instruction

The instructor provided feedback that helped me un.350 derstand my strengths and weaknesses relative to the course's goals and objectives.

V31 - SP Open Communication

I felt comfortable participating in the course discussions. 
V23 - SP Open Communication

I felt comfortable interacting with other course partici-

pants.

V11 - SP Group Cohesion

I felt comfortable disagreeing with other course par-

ticipants while still maintaining a sense of trust.

V38 - Emotion

I felt comfortable expressing emotion through the on-

line medium.

V27 - SP Affective Expression

Online or web-based communication is an excellent medium for social interaction.

V6 - SP Affective Expressions

I was able to form distinct impressions of some course participants.

V35 Emotion

Emotion was expressed when connecting with other students.

V36 - Emotion

The instructor acknowledged emotion expressed by students.

V37 - Emotion

Expressing emotion in relation to expressing ideas was acceptable in this course.

V39 - Emotion

The instructor demonstrated emotion in online presentations and/or discussions.

V3 - CP Triggering Event

I felt motivated to explore content-related questions.

V4 - CP Triggering Event

Course activities piqued my curiosity.

V28 - CP Triggering Event

Problems posed increased my interest in course issues. 
V18 - CP Integration

Learning activities helped me construct explanations/

solutions.

V16 - CP Integration

Combining new information helped me answer ques-

tions raised in course activities.

V17 - CP Exploration

Brainstorming and finding relevant information

helped me resolve content-related questions.

V34 - TP Facilitation

The instructor was helpful in guiding the class towards understanding course topics in a way that helped me clarify my thinking.

V12 - CP Integration

Reflection on course content and discussions helped me understand fundamental concepts in this class.

V13 - CP Exploration

Online discussions were valuable in helping me appreciate different perspectives.

V30 - CP Resolution

I can apply the knowledge created in this course to my work or other non-class-related activities.

V32 - CP Resolution

I have developed solutions to course problems that can be applied in practice.

V1 - CP Resolution

I can describe ways to test and apply the knowledge created in this course.

V8 - TP Direct Instruction

The instructor provided feedback in a timely fashion.

V21 - CP Exploration

I utilized a variety of information sources to explore problems posed in this course. 
V19 - SP Group Cohesion

I felt that my point of view was acknowledged by other

course participants.

V25 - SP Affective Expression

Getting to know other course participants gave me a

sense of belonging in the course.

V14 - TP Facilitation

The instructor encouraged course participants to ex-

plore new concepts in this course.

V22 - TP Facilitation

The instructor helped to keep course participants en-

gaged and participating in productive dialogue.

In the case of double-loadings, consideration was given to either the theoretical alignment that made the most sense or the level of the eigenvalue. One item did not load to an eigenvalue of the minimum value of .350. The last four factors were made up of five items in total and may represent interpretations of the items or the nature of the learning experience, unique to this sample. The other five factors, representing 34 of 40 items, did cluster in ways that are interpretable.

According to the CoI model, social presence is indicated by three subcategories: affective expression, open communication, and group cohesion. Teaching presence is indicated by three subcategories: design and organization, facilitation of discourse, and direct instruction. Cognitive presence is identified by four subcategories: triggering events, exploration, integration, and resolution. In the validated measurement of this instrument, the factor analysis yields three factors representing the umbrella categories of social (nine items), teaching (13 items), and cognitive (12 items) presence.

With the addition of six new measurement items related to the experience of emotion in online environments, a nine-factor solution emerged. Five of these nine factors corresponded to the theoretical model in appropriate but incomplete ways. Factor one included nine of 13 items measuring teaching presence: design and organization (4), facilitation (3), and direct instruction (2). In addition, one measure of social presence, group cohesion, and one measure of emotion loaded with this factor. The second factor yielded four of nine measures of social presence: group cohesion (1), open communication (2), and affective expression (1). One item measuring emotion loaded with this factor.

Four measures of emotional presence and one of social presence, affective expression, cluster together in factor three. These four items refer to emotion as expressed by students and the instructor, in relation to ideas and in discussion and presentation.

Eleven of the 12 items designed to measure cognitive presence loaded together, but in two factors. The fourth factor in the nine-factor solution emerged from cognitive presence, trig- 
gering event (3), cognitive presence, exploration (2), and cognitive presence, integration (3). One teaching presence item, facilitation, loaded with this factor. This item referred to guidance on understanding that "helped clarify thinking." Factor five was made of the three cognitive presence, resolution, items.

Six items loaded either singly, in pairs, or without a valid eigenvalue. These items were not seen as indications of individual concepts but rather idiosyncratic representations of this sample.

\section{Discussion}

Our research involved two phases. In the first phase, we considered the possibility that the online experience elicited, and is steeped in, emotion. We confirmed that emotion is present for students 1) when they discuss the online experience, and 2) in the experience of engaging in online learning. In addition, we began to see the type of emotion that exists in one, the other, or both. This begins to add the 'what' and 'when' of the emotional experience to earlier work that suggests emotion is present in the online experience (Artino, 2009; Cleveland-Innes, Garrison, \& Kinsel, 2007; Conrad, 2002; Zembylas, 2008).

The challenge of identifying, labeling, and discussing the subjective, emotional experience in text-based evidence makes it difficult for us to precisely define each emotive response and label from this data. We noted several regular patterns, giving us confidence we were getting closer to the real picture of the emotional experience of working online. First, text from the more complex interaction found in conference postings, compared to single-person response to questions in a survey instrument, demonstrated more numerous, complex, and interrelated emotional tone. Second, in spite of this difference in complexity, emotional range was very similar. Nine emotional responses were common to the experience of discussing the online experience and the experience itself as indicated in Table 1. Finally, this range of emotion was somewhat bounded; Plutchick's taxonomy of human emotion covers a far greater range than what was identified here. It is possible that certain emotions are notable in relation to learning and others less common.

In the second phase of this research, emotional presence indicators were added to the measurement of the three current theoretical elements that make up a community of inquiry. Given the range of emotional language expressed in the text of discussion forums and in the text describing the experience of being an online student, we submit that emotion is experienced by online students in areas beyond the expression of social presence.

Garrison, Anderson, and Archer (2000) define social, cognitive, and teaching presence in the following ways.

Social presence: The ability of participants in a community of inquiry to project themselves socially and emotionally, as 'real' people (i.e., their full personality), through the medium of communication being used.

Cognitive presence: The extent to which learners are able to construct and confirm meaning 
through sustained reflection and discourse in a critical community of inquiry.

Teaching presence: The design, facilitation, and direction of cognitive and social processes for the purpose of realizing personally meaningful and educationally worthwhile learning outcomes.

Emotion is noticeably absent from the discussion of teaching and cognitive presence. Emotion and affective response is part of social presence, and any connection with cognitive and teaching presence is deemed to occur through an overlap with social presence. Lipman (2003), the original creator of the community of inquiry notion for higher education, doesn't make the same distinction. For Lipman, emotive experience integrates with thinking to improve reason and judgment.

In emotional presence as measured here, the emotive experience does exist in combination with social presence, but it also clusters together as a unique presence. While Garrison (2007) suggests that "the face-to-face environment can more easily provide socio-emotional support"(p. 64), such support is essential online, beyond socio-emotional support to negotiating emotion that exists in and of itself, in relation to teaching and cognition. Based on our data, emotional presence is not just the affective response that presents itself through social presence; rather, it underpins the broader online experience. We define emotional presence as the following:

Emotional presence is the outward expression of emotion, affect, and feeling by individuals and among individuals in a community of inquiry, as they relate to and interact with the learning technology, course content, students, and the instructor.

This emotion will emerge as part of the transition to online learning and in the learning experience itself. In spite of evidence that more and more students are engaging in online learning (Allen \& Seaman, 2010), clarity about the transition to a new learning environment is still unconfirmed (Cleveland-Innes, Garrison, \& Kinsel, 2007). While new technologies are often expected to make work easier, they also involve the development of new competencies (Birch, 2001). For Birch, the dimensions of these new competencies are not yet clear; implementation of new technology for learners has sped well ahead of our understanding of necessary competencies. This creates two problems. One is that learners are left to create their own understanding and develop the skills to succeed in this technologically mediated environment. Second is that the emotion created by dealing with this new learning environment is still to be addressed. Knowledge about the impact of emotion on learning broadly (Brookfield, 2006; Lipman, 2003) is starting to emerge, but we are at early stages of discerning appropriate actions by students and teachers online, let alone being able to explain how emotion impacts online learning. 
It is beyond the scope of this paper to discuss the pattern of factors somewhat different from the original factor analysis that tested this instrument. The cluster of items was supportive enough of the original model that we feel confident suggesting that emotional presence may exist in combination with other presences theorized and measured as part of an online community of inquiry.

\section{Expanding the Online Community of Inquiry}

An online community of inquiry is a distinct personal and public search for community, meaning, and understanding. New roles are necessitated by the nature of the communication, which compels students to assume greater responsibility for, and control over, their learning. Under this enhanced communication, "each form of transport not only carries, but translates and transforms the sender, the receiver and the message" (McLuhan, 1995, p. 90). In addition to onlinedness (Hughes, 2004), a collaborative learning community necessitates the adoption of personal responsibility and shared control. This goes to the heart of an online learning community-a significant shift from the transmission of information in the lecture hall and the passive role of students.

Thus, online learning communities demand role adjustments. In the context of a new social role, the pathway to competence will occur over time as the role becomes prevalent and normalized. In this early stage, online communities will contribute to the socialization process for those engaging in this new role. The result is a new role and a new identity for learners. While the adoption and enactment of social roles is a standard, commonplace element of everyday experience, becoming an online learner has a unique characteristic. For many learners, role models for learning the required and expected activities are not present until one is already engaged in an online course (Garrison \& Cleveland-Innes, 2004). Emotion presents itself at two junctures: one in relation to the adjustment to a new role as online learner and the second in combination with cognitive, social, and teaching presence. This supports the detailed work of Zembylas (2008), an example of the emotional adjustment process and the positive and negative emotions that influence students' online learning experiences.

In this regard, we propose that ongoing analysis of emotions through the lens of the CoI framework will allow us to organize and develop appropriate interventions and thus new learning environments in which students can adjust to the new role and develop their social, emotional, teaching, and cognitive presences more effectively. Employing the CoI framework enables a comprehensive view of the dynamic and complex nature of online learning, including emotion. The three elements of the framework (i.e., social, teaching, and cognitive presence) present the main aspects of an online learning experience that cause and/or affect emotional arousal.

The implications of the emotional presence confirmed in this study are explained by Lehman (2006); emotions create presence as "presence is the result of the dynamic interplay between emotion, behaviour, cognition and the environment" (p. 13). Lehman further explains that individuals are perceptual by nature and dynamically interacting within the perceptual field to create representation of the world; throughout this dynamic, enactive pro- 
cess emotions affect behavior and cognition and impact our experience of presence. They are key to the interaction process in the perceptual world in that they focus our perceptions on particular aspects of a situation and enable us to concentrate on specific situations, connect the affective to the cognitive, and arrive at thoughtful and appropriate decisions.

\section{Conclusions}

Emotion may constrain learning as a distracter but, if managed, may serve as an enabler in support of thinking, decision making, stimulation, and directing. Online learning is replete, not fraught, with emotion. We conclude, with others, that emotion is present in online learning communities (Campbell \& Cleveland-Innes, 2005; Derks, Fischer, \& Bos, 2007; Marchand \& Gutierrez , 2011; O’Regan, 2003; Lehman, 2006; Perry \& Edwards, 2005). Research on emotional presence within an online community of inquiry demonstrates the salience of emotion in online learning. Given this reality, emotion must be considered, if not a central factor, at least as a ubiquitous, influential part of learning-online and otherwise (Plutchick, 2003; Stets \& Turner, 2006; Wosnitza \& Volet, 2005). Therefore, emotions expressed in the online experience, as explained by the CoI model (Garrison, Anderson \& Archer, 2000), indicate that emotional presence exists in social, cognitive, and teaching presence.

Our exploratory study must now be replicated with deductive emotional coding structures and larger samples to validate our exploratory statistical analysis. Future research requires that we determine first which emotions are present in common human exchanges and in any learning environment then identify if emotions in online environments are the same or different. Key to online environments is to acknowledge and discuss emotional tenor as much communicative information is lost without tone of voice and facial expressionsemoticons excepted. The exploration of emotional states that are not present- hidden yet influential-needs attention.

With evidence that emotions exist in all aspects of an online community of inquiry, consideration of the appropriate response is next. How does this impact design and organization, facilitation, and direct instruction? Which emotions, if any, are found uniquely in the triggering events, exploration, integration, and resolution found in cognitive presence? And what of the overlaps in all three presences and the possible emotion that may exist there? In addition, emotion and online learning may be explored in pedagogical models other than the CoI.

At the end of our deliberations, we define emotional presence as an experience that is salient in the online environment. It is a topic worthy of further study. In common practice, emotions are unexamined, seemingly visceral and unconscious. This is not appropriate in reflective pedagogy designed to bring cognition to consciousness. Learners need to understand the role of emotion in life and in learning to realize their benefits. This moves learners beyond the role of unaware victim of the human emotion response to conscious manager of emotion. Instructors can model emotional response (Brookfield, 2006) and its place in 
the instructor's own learning (Kort, Reilly \& Picard, 2001) and teach how to bring emotion to consciousness and make use of the emotional state in a learning situation (Campbell \& Cleveland-Innes, 2005). “As an instructor, it's crucial that you set up the learning situation in a manner that arouses learners' feelings of security, well-being, and self-confidence. It's equally important to challenge them without threats, intimidation, or pressure" (Weiss, 2000, p. 3). 


\section{References}

Akyol, Z., Arbaugh, B., Cleveland-Innes, M., Garrison, R., Ice, P., Richardson, J., \& Swan, K. (2009). A response to the review of the community of inquiry framework. Canadian Journal of Distance Education, 23(2), 123-136.

Allen, I. E., \& Seaman, J. (2010). Learning on demand: Online education in the United States, 2009 (Research Report No. 7). Retrieved from http://www.sloanc.org/ publications/survey/pdf/learningondemand.pdf

Anderson, T. (2007). Social and cognitive presence in virtual learning environments. Keynote lecture, CHAIS Conference, The Open University of Israel. Retrieved from http://www.slideshare.net/terrya/social-and-cognitive-presence-in-virtuallearning-environments

Arbaugh, J. B., Cleveland-Innes, M., Diaz, S., Garrison, D. R., Ice, P., Richardson, J. C., Shea, P., \& Swan, K. (2009). Developing a community of inquiry instrument: Testing a measure of the Community of Inquiry framework using a multi-institutional sample. The Internet and Higher Education, 11, 133-136.

Artino, A. R. Jr. (2009). Think, feel, act: Motivational and emotional influences on military students' online academic success. Journal of Computing in Higher Education, $21,146-166$.

Artino, A. R. Jr. (2010). Online or face-to-face learning? Exploring the personal factors that predict students' choice of instructional format. Internet and Higher Education, 13(4), 272-276.

Artino, A. R. Jr., \& Stephens, J. M. (2006). Learning online? Motivated to self-regulate? Academic Exchange Quarterly, 10, 176-182.

Barbalet, J. (2002). Introduction: Why emotions are crucial. In J. Barbalet (Ed.), Emotions and sociology (pp. 1-19). Oxford: Blackwell.

Baumeister, R. F., DeWall, C.N., \& Zhang, L. (2007). Do emotions improve or hinder the decision making process? In K. D. Vohs, R. F. Baumeister, R. F. \& G. Loewenstein (Eds.), Do emotions help or hurt decision making? A hedgefoxian perspective (pp. 11-31). New York: Russell Sage.

Birch, D. (2001). e-Learner Competencies. Retrieved from http://www.brightways.net/Articles/wpo1 elc.pdf

Bowlby, J. (1969). Attachment and loss (Vol. I). New York: Basic Books.

Brookfield, S. D. (2006). The skillful teacher: On technique, trust and responsiveness in the classroom. San Francisco: Jossey-Bass. 
Callahan, J. L. (2004, Summer). Breaking the cult of rationality: Mindful awareness of emotion in the critical theory classroom. New Directions for Adult and Continuing Education, 102, 75-83.

Campbell, P. \& Cleveland-Innes, M. (2005, August). Affect as presence in online communities of inquiry. Proceedings of 21st Annual Conference of Distance Teaching and Learning, Madison, WI.

Cleveland-Innes, M., Garrison, R., \& Kinsel, E. (2007). Role adjustment for learners in an online community of inquiry: Identifying the needs of novice online learners. International Journal of Web-based Learning and Teaching Technologies, 2(1), 1-16.

Cleveland-Innes, M., \& Campbell, P. (2006, November). Understanding emotional presence in an online community of inquiry. Paper presented at the 12th Annual SLOAN-C ALN Conference, Orlando, Florida.

Conrad, D. (2002). Engagement, excitement, anxiety, and fear: Learners' experience of starting an online course. American Journal of Distance Education, 16(4), 205226.

Cottrell, S. (2005). Critical thinking skills: Developing effective analysis and argument. London: Palgrave Macmillan.

Damasio, A. R. (1994, October). Descartes' error and the future of human life. Scientific American, 144-145.

Damasio, A. R. (1995). Descartes'error: Emotion, reason and the human brain. New York: Quill.

Damasio, A. R. (1999). The feeling of what happens: Body and emotion in the making of consciousness. Orlando, FL: Harcourt.

Damasio, A. R. (2003). Looking for Spinoza: Joy, sorrow and the feeling brain. Orlando, FL: Harcourt.

Davidson, R. J. (2003). Seven sins in the study of emotion: Correctives from affective neuroscience. Brain and Cognition, 52, 129-132.

Dirkx, J. M. (2008). The meaning and role of emotions in adult learning. New Directions for Adult and Continuing Education, 120, 7-18.

Dirkx, J.M. (1998). Knowing the self through fantasy: Toward a mytho-poetic view of transformative learning. Proceedings of the Adult Education Research Council. Retrieved from http://www.adulterc.org/Proceedings/1998/98dirkx.htm

Derks, D., Fischer, A.H., \& Bos, A. (2008). The role of emotion in computer-mediated communication: A review. Computer Human Behavior, 24, 766-785. 
Dirkx, J. M., \& Cranton, P. (Eds.) (1997). Nurturing soul in adult learning. New Dimensions for Adult and Continuing Education, 74, 79-88.

Eich, E., Kihlstrom, J. F., Bower, G. H., Forgas, J. P., \& Niedenthal, P. M. (2000). Cognition and emotion. Oxford: Oxford University Press.

Gardner, H. (1998). A multiplicity of intelligences. Scientific American Presents, 9(4), 1823.

Gardner, H., Kornhaber, M. L., \& Wake, W. K. (1996). Intelligence: Multiple perspectives. Belmont, CA: Wadsworth/Thomson Learning.

Garrison, D. R. (2007). Online community of inquiry review: Social, cognitive, and teaching presence issues. Journal of Asynchronous Learning Networks, 11(1), 61-72.

Garrison, D. R., \& Cleveland-Innes, M. (2004). Critical factors in student satisfaction and success: Facilitating student role adjustment in online communities of inquiry. In J. Bourne \& J. C. Moore (Eds.), Elements of quality online education: Into the mainstream. Vol. 5 in the Sloan C Series (pp. 29-38). Needham, MA: The Sloan Consortium.

Garrison, D. R., Anderson, T., \& Archer, W. (2000). Critical inquiry in a text-based environment: Computer conferencing in higher education. The Internet and Higher Education, 2, 1-19.

Goleman, D. (1995). Emotional intelligence: Why it can matter more than IQ. New York: Bantam Books.

Goleman, D. (1998). Working with emotional intelligence. New York: Bantam Books.

Gronlund, N. E. (2000). How to write and use instructional objectives. Toronto: PrenticeHall.

Hughes, J. (2004). Supporting the online learner. In T. Anderson \& F. Elloumi (Eds.), Theory and practice of online learning. Athabasca, AB: AU Press.

Ingleton, C. (2000). Emotion in learning - a neglected dynamic. In R. James, J. Milton, \& R. Gabb (Eds.), Research and development in higher education. Vol. 22 of Cornerstones of Higher Education (pp. 86-99). Melbourne, AU: Research and Development Society of Australasia..

Kang, M., Kim, S., \& Park, S. (2007). Developing emotional presence scale for measuring students' involvement during e-Learning process. In C. Montgomerie \& J. Seale (Eds.), Proceedings of World Conference on Educational Multimedia, Hypermedia and Telecommunications 2007 (pp. 2829-2832). Chesapeake, VA: AACE.

Kort, B., Reilly, R., \& Picard, R. (August, 2001). An affective model of interplay between 
emotions and learning: Reengineering educational pedagogy -Building a learning companion. Proceedings of International Conference on Advanced Learning Technologies (ICALT 2001). Madison, WI.

Krathwohl, D. (2002). A revision of Bloom's taxonomy: An overview. Retrieved from http:// www.unco.edu/cetl/sir/stating outcome/documents/Krathwohl.pdf

LeDoux, J. (1996). The emotional brain: The mysterious underpinnings of emotional life. New York: Simon \& Schuster.

LeDoux, J. (2002). The synaptic self: How our brains become who we are. New York: Penguin.

Lehman, R. (2006). The role of emotion in creating instructor and learner presence in the distance education experience. Journal of Cognitive Affective Learning, 2(2), 1226.

Linnenbrink-Garcia, L., \& Pekrun, R. (2011). Student emotions and academic engagement. Contemporary Educational Psychology, 36(1), 1-3.

Lipman, M. (1991). Thinking in education. Cambridge: Cambridge University Press.

MacCallum, R. C., Widaman, K. F., Zhang, S., \& Hong S. (1999). Sample size in factor analysis. Psychological Methods, 4, 84-99.

Marchand, G. C., \& Gutierrez, A. P. (2011). The role of emotion in the learning process: Comparisons between online and face-to-face learning settings. The Internet and Higher Education, 15(3), 150-160. doi:10.1016/j.iheduc.2011.10.001.

Merriam, S. B., \& Heuer, B. (1996). Meaning-making, adult learning and development: A model with implications for practice. International Journal of Lifelong Education, 15(4), 234-255.

McLuhan, M. (1995). Understanding media: The extensions of man. Cambridge: MIT Press.

Morrison, G.,R., Ross, S.,M., \& Kemp, J.,E. (2004). Designing effective instruction. Hoboken, NJ: John Wiley \& Sons.

Neuman, W. L. (2006). Social research methods: Qualitative and quantitative approaches ( $6^{\text {th }}$ ed.). New York, NY: Pearson Publishing.

O'Regan, K. (2003). Emotion and e-learning. Journal of Asynchronous Learning Networks, 7(3), 78-92.

Pekrun, R., Goetz, T., Titz, W., \& Perry, R. P. (2002). Academic emotions in students' self regulated learning and achievement: A program of qualitative and quantitative re- 
search. Educational Psychologist, 37(2), 91-105.

Perry, B., \& Edwards, M. (2005). Exemplary online educators: Creating a community of inquiry. Turkish Online Journal of Distance Education, 6(2), 46-54. Retrieved from http://tojde.anadolu.edu.tr/tojde18/index.htm

Plutchick, R. (2003). Emotions and life. Washington, DC.: American Psychological Association.

Preacher, K. J., \& MacCallum, R. C. (2002). Exploratory factor analysis in behavior genetics research: Factor recovery with small sample sizes. Behavior Genetics, 32, 153-161.

Rovai, A. P. (2002). Sense of community, perceived cognitive learning, and persistence in asynchronous learning networks. The Internet and Higher Education, 5(4), 319-332.

Schutz, P. A., \& Lanehart, S. J. (2002). Introduction: Emotions in education. Educational Psychologist, 37, 67-68.

Shea, P. (2006). A study of students' sense of learning community in online environments. Journal of Asynchronous Learning Networks, 1O(1). Retrieved from http://sloanconsortium.org/jaln/v1on1/study-students\%E2\%80\%99-sense-learning-community-online-environments

Stets, J. E., \& Turner, J. H. (Eds.) (2006). Handbook of the sociology of emotions. New York: Springer.

Thompson, T. L., \& MacDonald, C. J. (2005). Community building, emergent design and expecting the unexpected: Creating a quality eLearning experience. The Internet and Higher Education, 8(3), 233-249.

Värlander, S. (2008). The role of students' emotions in formal feedback situations. Teaching in Higher Education, 13(2), 145-156.

Waxman, H. C., Lin, M.-F., \& Michko, G. M. (2003). A meta-analysis of the effectiveness of teaching and learning with technology on student outcomes. Retrieved from http://www.ncrel.org/tech/effects2/

Weiner, B. (1985). An attributional theory of achievement motivation and emotion. Psychological Review, 92(4), 548-573.

Weiss, R. (2000). Emotion and learning - Implications of new neurological research for training techniques. Training and Development, 16 . Retrieved from http://findar-

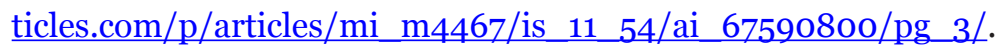

Wosnitza, M., \& Volet, S. (2005). Origin, direction and impact of emotions in social online learning. Learning and Instruction, 15(5), 449-464. 
Zembylas, M. (2008). Adult learners' emotions in online learning. Distance Education, 29(1), 71-87.

\section{Athabasca University $\mathbf{1}$}

(c) (i) 